\title{
7
}

\section{Immunoassays Using Artificial Nanopores}

\author{
Paolo Actis, Boaz Vilozny and Nader Pourmand \\ Department of Biomolecular Engineering, Baskin School of Engineering, \\ University of California Santa Cruz, \\ USA
}

\section{Introduction}

\subsection{Scope}

Artificial nanopores can be loosely defined as materials possessing one or more nanometersize pores (1-100 $\mathrm{nm}$ in diameter). This recent class of nanostructures is generating great interest in the scientific community as a platform for biomolecular analysis. The first fabrication of an artificial nanopore with true nanometer control dates to 2001 (Li et al., 2001) but the application of nanopores for biological studies started 10 years earlier. Following a rapid review of the highlights of 20 years of nanopore science, we explore the advancement of nanofabrication techniques that allowed the creation of individual nanopores, nanopore arrays, and nanoporous materials. Although most of the methods currently used to fabricate nanopores require expensive equipment and highly-skilled technicians, we focus here upon those technologies that allow the fabrication of nanopores at the bench and discuss signal transduction mechanisms that allow nanopores to be used as biosensors. In particular, we review the creative application of nanopipettes, artificial nanopores that can be easily fabricated from inexpensive glass capillaries, as a biosensing platform and discuss their potential for immunosensing.

\subsection{History of nanopores}

The concept of employing a nanopore for biological studies was initiated in the early 1990's by David Deamer (UC Santa Cruz) in collaboration with Daniel Branton (Harvard University), and independently by George Church and Richard Baldarelli (Harvard Medical School). Their hypothesis was that a DNA molecule threaded through a nanopore would perturb the ionic current in a sequence-specific fashion. This concept, however, required a very small pore of molecular dimensions to thread a long strand of DNA.

The first experimental evidence of whether a nanopore could detect nucleic acids was reported by Kasianowicz and coworkers in 1996 (Kasianowicz et al., 1996). The authors threaded single stranded DNA and RNA molecules through an $\alpha$-haemolysin pore by means of an external applied voltage. Isolated from Staphylococcus aureus, $\alpha$-haemolysin is a $33 \mathrm{kDa}$ membrane pore protein whose channel remains open at neutral $\mathrm{pH}$ and high ionic strength and whose pore diameter is $\sim 2 \mathrm{~nm}$ (Song et al., 1996). The passage of each molecule was detected as a transient decrease of ionic current whose duration was proportional to the polymer length. From the very first paper published using nanopore technology, the 
authors envisioned that such a device would allow direct, ultra-fast DNA sequencing. The initial optimism was boosted by the discovery that one can distinguish adenine from cytosine within an RNA molecule with a heterosequence $A_{30} C_{70}$ (Akeson et al., 1999).

The initial excitement diminished when scientists realized that the signal-to-noise ratio was insufficient to ever reach single-base resolution in translocation experiments under typical conditions. The main obstacle is that translocation through $\alpha$-haemolysin occurs at such a high rate that statistical fluctuations mask subtle differences among the four different bases. The fact that well-defined chemical and structural changes can be introduced to $\alpha$ haemolysin by genetic engineering still offers the promise that a sequencing device can be built out of a biological nanopore. However, biological nanopores hold some inherent limitations. In particular, they need to be embedded in a supporting lipid bilayer whose stability is closely dependent on $\mathrm{pH}$, temperature, electrolyte concentration, and mechanical stress. Even as research on these protein-based pores was progressing, improved nanofabrication techniques have made it possible to artificially sculpt nanopores into inorganic surfaces with nanometer precision. The possibility of precisely tuning nanopore size and geometry has made possible an expansion of nanopore-sensing technologies (Fig. 1). Applications include the detection of small molecules, peptides, enzymes, proteins and protein complexes (Siwy\&Howorka, 2010).
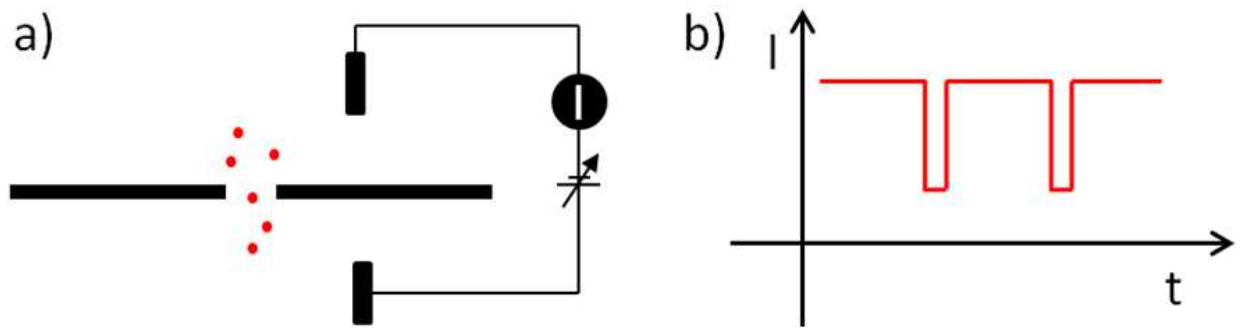

Fig. 1. Scheme illustrating the principle of nanopore measurements. a) A transmembrane potential causes a constant ion flow which is $\mathrm{b}$ ) temporary perturbed by analytes passing through the nanopore.

Until now, DNA sequencing has been the application of choice for nanopores. The potential of a sequencing device that doesn't require (labelled) nucleotides, polymerases or ligases, requires a minimal sample preparation and allows long reads $(>10,000 \mathrm{nt})$ still inspires several research groups (Branton et al., 2008). Nanopore research is, however, by no means limited to DNA sequencing, and the goal of this chapter is to highlight the recent advances in immunosensing using artificial nanopores, a platform that has the potential for myriad applications.

\section{Fabrication of artificial nanopores}

Naturally occurring and synthetic zeolites are perhaps the archetypical nanoporous materials, but their sub-nm pores make them more suitable for gas storage rather than for biosensing (Morris\&Wheatley, 2008). In this section, we review the fabrication of nanopores and nanoporous materials with cavities of $\sim 2 \mathrm{~nm}$ and above. We will first discuss the fabrication of individual nanopores and nanopore arrays using nanolithography, while we 
dedicate separate sub-sections to bench-top fabrication methods and fabrication of nanoporous materials.

\section{1 lon and electron-beam sculpting}

In 2001, $\mathrm{Li}$ and coworkers ( $\mathrm{Li}$, et al., 2001) reported the first fabrication of a nanopore with true nanometer control using a method called ion beam sculpting. The authors developed a focused ion beam (FIB) machine that uses ions to mill a tiny hole in a silicon nitride membrane. Their system was equipped with ion detectors as a milling feedback-control. Interestingly, they observed that ion rate and temperature affected pore dimensions, causing shrinkage and enlargement, fine-tunable with nanometer precision. Cees Dekker's group (Storm et al., 2003) developed a different approach based on electron beam lithography followed by etching. As with Li's method, pore size could be modified, in this case by exposure of the nanopore to a high-intensity wide field illumination (Fig. 2D). Holes with a diameter greater than the membrane thickness grew in size, whereas smaller holes shrank. Several other groups reported the use of a transmission electron microscope (TEM) to drill nanopores in thin membranes thus making the laborious preparation for electron-beam lithography unnecessary (Zandbergen et al., 2005) (Kim et al., 2006) (Krapf et al., 2005). Traditionally, insulating oxides were used as the material of choice for nanopore fabrication due to their robustness, chemical stability, and wide availability. More recently, scientists started fabricating nanopores into conductive or semi-conductive materials.

Graphene is a two-dimensional layer of carbon atoms packed into a honeycomb lattice with a thickness of only one atomic layer $(\sim 0.3 \mathrm{~nm})$. Despite its minimal thickness, graphene is robust as a free-standing membrane. In addition, graphene is an excellent electrical conductor (Geim\&Novoselov, 2007). Independently, three groups showed the fabrication of nanopores in graphene (Garaj et al., 2010, Merchant et al., 2010, Schneider et al., 2010) by electron beam milling (Fig. 2E). Preliminary results showed that current blockades due to DNA translocation through graphene nanopores are larger than what has been observed for silicon nanopores of the same diameter. On the other hand, the authors showed that bare graphene devices exhibited large ion current noise and suffered from low yields.

Another very popular technique to fabricate artificial nanopores is the track-etching method (Fig. 2B,C). This technique is based on the irradiation of a polymer foil with energetic heavy ions followed by preferential chemical etching of the particle tracks (Siwy et al., 2003). Cylindrical or conical pores with diameters from a few nanometers to the micrometer range can be obtained. Individual nanopores can be fabricated by masking the polymer foil with a metal during the ion irradiation. Track-etched nanopores can be coated with gold to create individual conical gold nanotubes or nanotube arrays (Martin et al., 2001).

\subsection{Bench top fabrication}

All nanopore fabrication methods described above require expensive equipment, such as TEM or FIB, or access to heavy ion accelerators. Nanopipettes are a class of artificial nanopores that can be easily fabricated at the bench starting from inexpensive glass capillaries (Fig. 2A). Quartz is the material of choice to fabricate nanopipettes. It possesses many advantages compared to other glasses in term of optical transparency, electrical noise, and mechanical properties. The most widely adopted fabrication method for nanopipettes is 


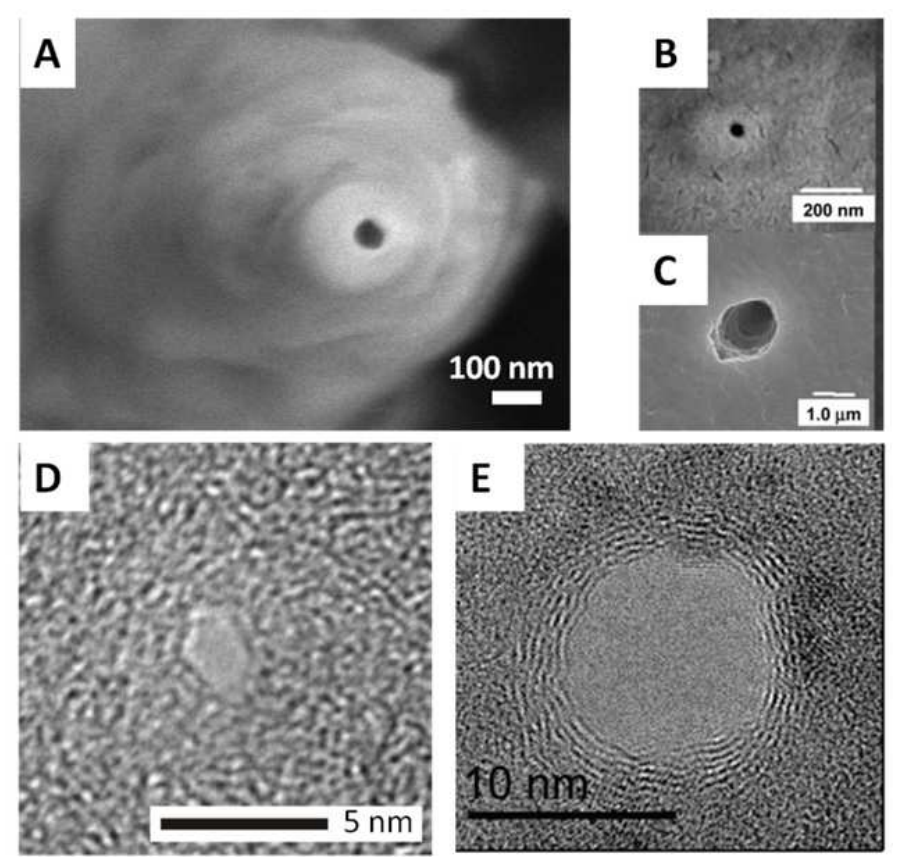

Fig. 2. Electron microscopy of nanopores A) laser-pulled nanopipette, adapted with permission from (Umehara et al., 2006). Copyright 2006 American Chemical Society. Tracketched nanopore in polycarbonate showing respectively B) surface of the membrane exposed to the etch solution and C) surface exposed to the stop solution showing tip opening, adapted with permission from (Harrell et al., 2006). Copyright 2006 American Chemical Society. D) Nanopore in a $\mathrm{SiO}_{2}$ membrane. Adapted with permission from (Storm, et al., 2003) and E) graphene nanopore. Adapted with permission from (Merchant, et al., 2010). Copyright 2010 American Chemical Society.

laser pulling of a glass capillary. A laser beam is focused on the glass tubing until it reaches its softening point. A hard pull is then applied with a preset delay to generate two identical nanopipettes. The major advantage of the laser pulling method is the simplicity of the approach; there is no need for expensive equipment, clean rooms, or specialized technicians.

Fabrication of nanopipettes with nanometer precision remains technically challenging and alternative methods have been proposed to increase the reproducibility of pore dimensions. Ding and colleagues (Ding et al., 2009) reported an etching protocol to enhance the reproducibility of the nanopore size. First the capillary was pulled into a micropipette and then the very tip was sealed by a heat treatment. A nanopore was opened by external etching and monitored through electrochemical measurements, in order to attain the desired pore size.

Significant effort has been invested in fabricating nanopipettes from materials other than glass. Kim and colleagues (Kim et al., 2005) fabricated carbon nanopipettes with large aspect ratios (length/diameter) based on the glass pulling technique. First, they created an aluminosilicate nanopipette with a conventional laser puller, after which they catalytically deposited carbon layers onto the exterior and interior of the nanopipette. The exterior carbon layer and the glass 
layer are subsequently removed by chemical etching, exposing the interior carbon nanopipette tip structure. Freedman and coworkers (Freedman et al., 2007) employed magnetic techniques to affix a magnetized carbon nanotube (mCNT) to the tip of a conventional glass nanopipette. The resulting mCNT-tipped nanopipettes were sufficiently robust that they could be used to penetrate cell membranes and to allow fluidic transport.

Zhang and coworkers (Zhang et al., 2004) developed the "nanopore electrode" which consists of atomically sharp platinum wire sealed into a glass capillary. By fine polishing, they exposed a platinum disk of nanometer dimension, and a subsequent etching step produced a truncated cone shaped nanopore embedded in glass, where the bottom of the pore is defined by the platinum disk.

\subsection{Nanoporous materials}

Numerous methods have been developed to fabricate nanoporous films and materials. We will limit the description to materials already employed for immunosensing whose applications will be described in the Section 3: "Nanoporous structures as loading materials for immunoassays".

Anodized aluminum oxide (AAO) has been one of the substrates of choice for the fabrication of nanoporous materials. AAO membranes are fabricated by anodic oxidation of an aluminum substrate in acidic solutions. The resulting membrane consists of densely packed hexagonal pores of 10-200 nm in diameter, whose size depends on the oxidation conditions (Stroeve\&Ileri, 2011). Architectures consisting of long-range ordered nanochannel arrays can be fabricated out of AAO on the millimeter scale (Masuda et al., 1997).

Nanoporous films can be prepared by template-assisted synthesis as well. The self-assembly of polystyrene nanospheres and $5 \mathrm{~nm} \mathrm{SiO} 2$ nanoparticles on a glass slide followed by a calcination process produces an ordered array of nanopores embedded in a $\mathrm{SiO}_{2}$ matrix (Yang et al., 2008). The application of more volatile template materials was used to create both carbon (Lee et al., 2001) and silica (Schmidt-Winkel et al., 1998) mesocellular foams. Moreover, nanoporous structures can be fabricated out of metallic materials. Ding and coworkers (Ding et al., 2004) demonstrated the synthesis of nanoporous gold film by selective dissolution (dealloying) of silver from a silver/gold alloy. Upon silver dissolution, gold atoms re-organize into an interconnected network of nanopores whose size can be tuned in the nanometer range via simple room-temperature post-processing.

Lin and coworkers (Lin et al., 2010) developed a very original method based on biogenic silica to create a nanoporous film on top of electrode materials. Diatoms are eukaryotic, unicellular photosynthetic algae that are ubiquitous in nearly every aquatic habitat. Diatoms produce diverse three-dimensional, regular silica structures (a.k.a. "frustules") with pores from nanometer to micrometer dimensions.

\section{Nanoporous structures as loading materials for immunoassays}

As discussed in the previous section, nanoporous materials are fundamentally different than solid state, "single-track" nanopores due to fabrication methods, size and geometry of the nanopores. A distinguishing feature is that nanoporous materials have a very large surface area, a property used in many immunoassay applications. Herein, we will review the application of nanoporous materials for immunosensing. 
Piao and co-workers constructed a highly stable immunoassay using signal-generating enzyme (as ELISA label) immobilized in mesocellular carbon foam (Piao et al., 2009). Mesoporous carbon possesses large pores (D $~ 31 \mathrm{~nm}$ ), interconnected by smaller windows (D $\sim 21 \mathrm{~nm}$ ) that are surrounded by small pores $(\mathrm{D} \sim 5.6 \mathrm{~nm})$. Acid treatment can easily introduce carboxylic moieties at the surface of mesoporous carbon, thus enabling immobilization of horseradish peroxidase (HRP) by cross-linking with glutaraldehyde. HRP can readily enter the large pores while small pores can act as a substrate transporting channel, facilitating the enzymatic reaction. Furthermore, the immobilization of enzyme into nanoporous materials leads to high enzymatic activity and stability, and protection from proteolysis while enhancing mass transport (Wang\&Caruso, 2004). The same group demonstrated that this approach give similar results when mesoporous silica was used (Piao et al., 2009).

$\mathrm{Li}$ et al ( $\mathrm{Li}$ et al., 2011) used ultra-thin nanoporous gold leaf to enhance the electrochemiluminescent detection of carcinoembryonic antigen (CEA). Nanoporous gold leaves are large-area, highly conductive and ultra-thin nanoporous gold membranes with uniform pore size distribution centered around 20-30 nm. The authors showed that the nanoporous film reduces electron injection barrier to quantum dots thus enhancing electrochemiluminescence. Shulga and coworkers synthesized a nanoporous gold (NPG) film by selective dissolution (dealloying) of silver from silver/gold alloy. Upon silver dissolution, gold atoms re-organize into an interconnected network of nanopores. Antibodies were immobilized within the nanoporous gold allowing the spectrophotometric detection of prostate specific antigen (PSA) (Shulga et al., 2008). Wei and coworkers employed the same material for the detection of PSA but used a label-free electrochemical transduction (Wei et al., 2011). Li and coworkers constructed a composite material from a nanoporous gold film and graphene sheets. The synergy between these two materials yielded to a highly conductive composite that could detect human serum chorionic gonadotropin (hCG) within the range 0.5$40.00 \mathrm{ng} / \mathrm{ml}$ with a detection limit of $0.034 \mathrm{ng} / \mathrm{mL}$ (Li et al., 2011). Ding et al. developed an electrochemical immunoassay using nanoporous gold (NPG) electrodes and enhanced the sensitivity of the method by using gold nanoparticles conjugated with horseradish peroxidase (HRP) labeled secondary antibody. They demonstrated the detection of hepatitis B surface antigen (HBsAg) with a dose response in the range of $0.01-1.0 \mathrm{ng} / \mathrm{mL}$ with a detection limit of $2.3 \mathrm{pg} / \mathrm{mL}$ (Ding et al., 2010).

Yang and coworkers constructed a highly efficient chemiluminescent immunoassay based on a biofunctionalized three-dimensional ordered nanoporous $\mathrm{SiO}_{2}$ film (Yang, et al., 2008). Lin and coworkers employed biogenic nanoporous silica (diatoms) to create a high density of nanowells where capture antibodies were immobilized. The performance of the biogenic silica membrane biosensor was tested in comparison with nanoporous alumina and plain metallic thin film biosensor. The authors showed an impressive linear range spanning 6 orders of magnitude, from $1 \mathrm{pg} / \mathrm{mL}$ up to $1 \mu \mathrm{g} / \mathrm{mL}$. Significant enhancement in the sensitivity and response time was attributed to enhanced diffusion of fluids within the diatoms nanochannels (Lin, et al., 2010).

\section{Methods of detection using nanopores}

Because nanopores comprise a wide variety of materials, there are many possible mechanisms to measure a signal for a nanopore-based assay. The most common techniques 
involve measuring electrolyte flux, or ionic current, through a pore that bridges two chambers. These methods are discussed in detail below (Section 4.1), as they often involve properties that only arise with nanopores. Other methods, employing functionalized nanopore sensors, are discussed in Section 4.2.

\subsection{Resistive-pulse sensing}

The technique known as resistive-pulse sensing derives from the well-known Coulter counter, in which particles such as individual cells pass through an aperture. If the aperture bridges two electrolyte-filled chambers containing polarized electrodes, then a particle causes a "pulse" of electrical resistance as it passes through the opening. By definition, then, this is a single-channel technique. Performing this technique with nanopores provides the exciting potential for the particles to include many types of biomolecules, including proteins and nucleic acids (Siwy\&Howorka, 2010).

For the purposes of immunoassays, the resistive-pulse technique offers a way to analyze biomolecules without labelling. The shape and duration of pulses can discriminate biomolecules, reveal conformational states of proteins, and show antibodies that are bound to antigens. As described by Charles Martin's group (Sexton et al., 2010), the size of proteins as well as their affinity with the pore walls contribute to their electrical translocation signature (Fig. 3). Techniques for analyzing proteins with artificial and biological pores have been recently reviewed (Movileanu, 2009). The wide range of sizes covered by proteins, antibodies, and even viruses makes artificial pores an important tool for analyzing biomolecules.

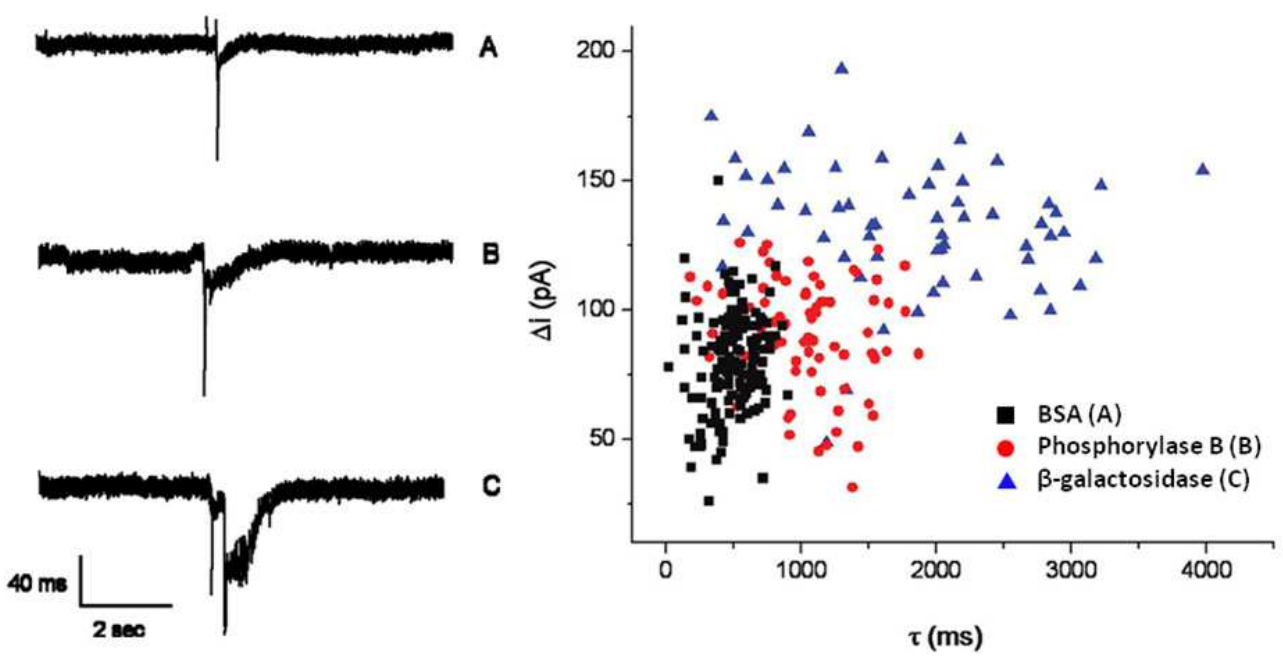

Fig. 3. Left: Ion current pulses arising from translocation of three proteins from tip to base of a conical nanopore with tip diameter of $17 \mathrm{~nm}$. The proteins are bovine serum albumin $(\mathrm{A})$, phosphorylase B (B), and beta-galactosidase (C). Right: scatter plot of the pulse amplitude $(\Delta \mathrm{I})$ and pulse duration $(\tau)$ for the three proteins. Reprinted with permission from (Sexton, et al., 2010). Copyright 2010 American Chemical Society. 
Several recent examples in the literature demonstrate the potential of resistive-pulse sensing to develop powerful immunoassays. In the context of translocation through a nanopore, "immunoprecipitation" can simply mean a change in pore blockade properties compared to individual antigens or individual antibodies. Also, because particles such as viruses can be on the order of $500 \mathrm{~nm}$, we will include micron-scale pores in our consideration of resistivepulse assays. Using $600 \mathrm{~nm}$ pores in glass, Uram, et al. were able to determine antibody binding to a virus based on translocation (Uram et al., 2006). The virions, with diameter of $200 \mathrm{~nm}$, increased in size roughly $60 \%$ on antibody binding. A few years earlier, pores of comparable size (1 micron diameter in PDMS) were used to detect binding of antibodies to biotin-derivatized colloids (Saleh\&Sohn, 2003).

Moving to pores less than $100 \mathrm{~nm}$ in diameter brings the technique of resistive pulse sensing into the realm of detecting native proteins and antibodies. These applications require no labelling of the protein, which can sometimes change binding properties. For example, the Martin group has shown that the electrical signature of a protein can be distinguished from that of the protein bound to an antibody fragment (Sexton et al., 2007). In that report, tracketched nanopores were coated with gold to make a conical nanotube of tip opening 9 to 27 $\mathrm{nm}$ in diameter. Electrophoretic translocation of biomolecules from tip-to-base of the nanopores gave characteristic pulse durations that were significantly longer for the immunocomplex than for protein or antibody fragment alone. Silicon nitride pores have been used in several studies of protein translocation. Using $28 \mathrm{~nm}$ pores in a membrane 20 $\mathrm{nm}$ thick, protein-protein interactions were observed in real-time (Han et al., 2008). More recently, $20 \mathrm{~nm}$ pores prepared using the focused ion beam (FIB) technique in silicon nitride membranes were used to discriminate native from unfolded proteins (Oukhaled et al., 2011). Another dimension was recently added to the resistive pulse nanopore techniques, in which artificial nanopores were coated with a "fluid wall" within which biotin was attached (Yusko et al., 2011). The translocation of streptavidin was markedly influenced by the interaction with the antigen. The promise of these new techniques is that they may one day replace immunoassays that require labelling, such as ELISA, and offer greater sensitivity and discriminatory power.

\subsection{Ion current modulation methods}

The resistive pulse technique measures brief translocation events recorded as "pulses" of resistance (or current). However, ion current can be modulated in other ways in order to give an analytical signal. For example, if a receptor is immobilized to the nanopore surface, then the presence of the target will cause a change in ion current as long as the target is bound. There is a growing arsenal of techniques for chemically modifying the surface of nanopores (Nguyen et al., 2011, Sexton, et al., 2007, Wanunu\&Meller, 2007). There is nothing about this particular sensing mechanism that requires nanoscale pores. But as with resistive pulse sensing, bringing the opening down to the scale of biomolecules provides increased sensitivity. Furthermore, there are some properties of ion current in nanopores that are not present in larger structures, and these can be exploited as a signalling mechanism.

The sensitivity of receptor-appended nanopores as analytical instruments depends not only on the binding affinity of the receptor for the analyte, but also on the ability for the binding to result in a modulation of ion current. Predictably, binding many large particles such as antibodies will increase resistance to ion flux through a pore. This was demonstrated with 
biotin-modified conical nanopores which showed a dramatic decrease in ion current in the presence of streptavidin at concentrations as low as $1 \mathrm{pM}$ (Ali et al., 2008). Quartz nanopipettes functionalized with biotin likewise responded to streptavidin, and were also responsive to the $18 \mathrm{kD}$ protein VEGF after immobilization of antibodies to the pore surface (Umehara et al., 2009) .

Another important consideration is the property of ion current rectification in conical and other types of asymmetric nanopores. This is a true nanoscale effect, and results from the interaction of ions with the electrical double layer formed at the surface of charged nanopores (Wei et al., 1997). The result is a "nanofluidic diode" (Vlassiouk et al., 2009) in which the ion current shows nonlinear dependence on applied voltage. This property is highly sensitive to surface charge, and thus such conical nanopores lend themselves to detection of charged analytes such as polyelectrolytes (Actis et al., 2011, Fu et al., 2009, Umehara, et al., 2006). To date, polyelectrolytes have been the primary targets for assays using this mechanism. Furthermore, it should be possible to target any analyte in which the binding results in a modulation of surface charge.

The use of receptor-appended nanopores for ion current modulation, rather than Coulter counting methods, broadens the technique to include all manner of nanoporous materials and is not limited to single-channel technique (Gyurcsányi, 2008). Despite the availability of many types of functionalized nanoporous materials, there are few examples of these used as ion current-based biosensors (Wang\&Smirnov, 2009). Two recent reports illustrate how nanoporous materials can be used for label-free immunosensing. Using a suspension of nanoparticles functionalized with streptavidin, biotin could be detected at a concentration as low as $1 \mathrm{nM}$ (Lei et al., 2010). This method is particularly versatile because there are many established techniques to functionalize nanoparticles. It is also noteworthy that in this case the analyte is very small compared to the receptor. In another example of modulating ion current with a small molecule analyte, glucose was detected using a receptor protein obtained from E. coli (Tripathi et al., 2006) where the histidine-tagged receptor was immobilized to a hybrid material consisting of nanoporous polycarbonate onto which gold was deposited using electroless plating. While the measurement of ion current through such membranes is relatively straightforward, reports in the literature of such sensors are scarce. This could be due to the difficulty in functionalizing nanomaterials, or perhaps to insufficient sensitivity in modulations of ion current.

A more common electrochemical technique for biosensing with nanoporous materials is to perform voltammetry using a redox indicator which can be detected as it diffuses through the nanoporous material. The nanoporous membrane can be affixed directly to the working electrode. A recent example is the measurement of biomarkers in whole blood using a nanoporous membrane derivatized with antibodies (de la Escosura-Muñiz\&Merkoçi, 2011). To amplify the signal, a secondary antibody was tagged with gold nanoparticles, which then catalyzed the deposition of silver to further block the pores. While this added some complexity to the assay, the device was able to perform using whole, unfiltered blood. Simpler schemes measuring diffusion of a redox active species have also been successful with a variety of nanoporous materials (Lin et al., 2009, Nguyen et al., 2009, Wei, et al., 2011). Singh and co-workers also showed the application of electrochemical impedance spectroscopy to detect peanut protein Ara h1 with an antibody-functionalized nanopore (Singh et al., 2010). 


\subsection{Label-free immunoassays with functionalized nanopipettes}

Our group pioneered the application of nanopipettes as a platform for label-free biosensing (Umehara, et al., 2009). The principles that govern transport properties through nanopipette are similar to conical nanopores in general. The ion current is rectified due to the surface charge and the conical shape of the pore (Wei, et al., 1997). When receptors are attached, the nanopipette can become an electrical biosensor.

We named this technology STING, as Signal Transduction by Ion Nano-Gating. The tip of a nanopipette was functionalized with protein $A / G$, a commercially available chimeric protein that captures the Fc region of an IgG molecule. This strategy allows the control over the orientation of antigen-binding sites which are always exposed to the analyte. As a proof of concept, two proteins associated with human colorectal cancer were detected, interleukin10 (IL-10) and vascular endothelial growth factor (VEGF). Exogenously added antigens instantly reduced the ionic flow through the nanopipette, an effect that was not detected in the control nanopipette functionalized with nonspecific antiferritin IgG. Unfortunately, a lack of reproducibility of pore dimensions and lot-to-lot variations in the surface functionalization did not allow for a more quantitative analysis of the observed current reduction. Theoretically, the limit of detection of the nanopipette platform is determined by the number of molecules that generate a detectable signal at the 50-nm tip. In practice, however, consumption of target molecules on surfaces of no sensitivity, such as the outer nanopipette sidewalls, could prevent devices from achieving the theoretical detection limit. Once the protocols were improved to limit the nanopipette functionalization to its inner walls, we were able to demonstrate the analytical applications of nanopipettes for the detection of mycotoxins (Actis et al., 2010)(Fig. 4).

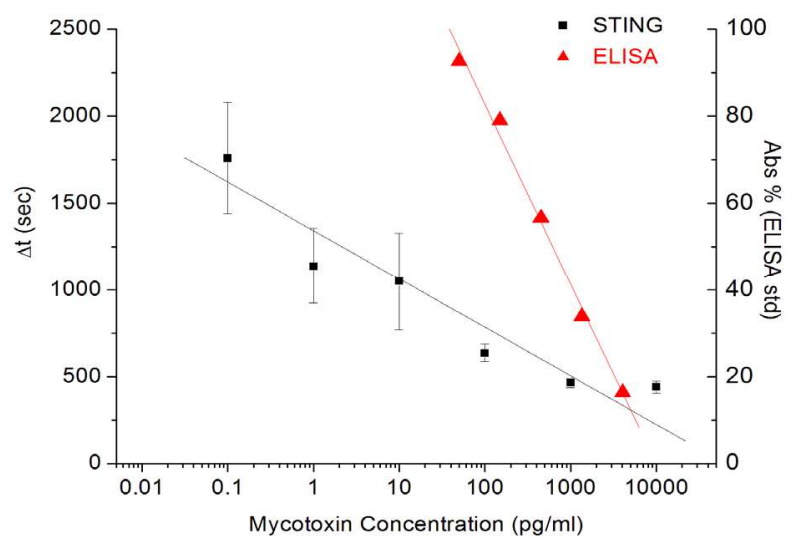

Fig. 4. Comparison between standard curves from ELISA kit (red triangles) and the STING sensor (black squares) for mycotoxin detection. Results show a dynamic range for the STING platform of at least 2 orders of magnitude with a detection limit 3 orders of magnitude lower than ELISA. Adapted with permission from (Actis, et al., 2010).

Mycotoxins are small, non polar molecules produced by fungi and are extremely toxic to mammals even in low concentrations. Using a nanopipette functionalized with antibodies specific to a mycotoxin, we showed a concentration dependent response. Indeed, the 
nanopipette platform achieved a dynamic range of 5 orders of magnitude with a detection limit 3 orders of magnitude lower than that of a commercially available ELISA kit for mycotoxin.

Despite these successes, antibody-based detection schemes suffer from several drawbacks including: production, cost, limited target analytes, and limited shelf life. To address these imitations, the use of aptamers instead of antibodies as specific receptors was explored. Aptamers are single-stranded oligonucleotides, designed through an in vitro selection process called SELEX (Systematic Evolution of Ligands by Exponential Enrichment) (Ellington\&Szostak, 1990, Tuerk\&Gold, 1990). Aptamers have similar affinity and selectivity for targets as antibodies, but they can be chemically synthesized, stored in ambient conditions, and easily regenerated. In addition, they can be engineered to undergo a largescale conformational response to specific molecules, largely affecting the ion transport through the nanopipette.

As a proof-of-concept, a thrombin-binding aptamer was immobilized on the surface of a nanopipette using standard carbodiimide coupling. The interaction of thrombin with its specific aptamer tethered on the nanopipette caused a partial occlusion of the nanopipette pore thus decreasing the ion flow. The decreased ion current can be directly correlated with thrombin concentration in both pure buffer solution and diluted serum. A major advantage of aptamers over antibodies is their ability to reverse the analyte binding. We showed that nanopipette sensors can be reused up to 5 times with minimal degradation of the sensor performance (Actis et al., 2011). In the long term, nanopipette technology promises to open new avenues for biomedical research, and promises breakthroughs in understanding of diseases at the single cell level.

\subsection{Potential of nanopipettes for single-cell immunoassay}

Nanotechnology-based tools having high sensitivity and low invasiveness hold great promises as new biomedical devices for single cell manipulation and intracellular analysis. We are currently developing a single-cell manipulation platform based on nanopipettes. As a nanopipette approaches the surface of a cell the ionic current through the pore will decrease due to "current squeezing", a well known effect, exploited to great benefit in scanning ion conductance microscopy (Hansma et al., 1989). By monitoring the ionic current the precise position of the nanopipette can be determined and controlled within $\sim 200 \mathrm{~nm}$ of the cell membrane. After initial positioning above the cell membrane the nanopipette can either be scanned over the cell membrane to render a topographical image (Klenerman \& Korchev, 2006) or inserted into the cell. The comparatively small size of the nanopipette combined with controlled penetration conditions maximizes cell viability.

By employing functionalized nanopipettes, detection of the interaction of intracellular, soluble antigens with antibodies immobilized on the nanopipette pore should be possible.

\section{Other detection methods}

To round out the discussion of nanopores and nanoporous materials in immunoassays, we will mention some non-electrochemical techniques. As with redox indicators, the diffusion of an optical indicator can be measured through a nanoporous membrane (Jágerszki et al., 2007). Such sensing schemes can potentially take advantage of distinctive recognition/transport 
phenomena that occur in nanostructures. Many of the other properties of nanoporous materials, such as high surface area, can also be exploited for sensing schemes. A recent example is the use of porous alumina functionalized with a capture protein (Alvarez et al., 2009). The binding of an antibody can be detected by optical interferometry. In theory, this method can be used with many types of nanomaterials and is not restricted to nanoporous structures.

\section{Conclusions}

Artificial nanopores represent a fundamental technological breakthrough. As with many new technologies, nanopores required interdisciplinary collaboration. Fittingly, then, the potential applications of this new technology are equally broad, ranging from sequencing to diagnostics, cell biology to biophysics. Going forward, the integration of nanopores with microfluidic or optofluidic platforms may generate self-contained biodetectors with single molecule sensitivity (Holmes et al., 2010). The fabrication of nanopores into materials of atomic thickness, such as graphene can dramatically improve signal-to-noise ratio in biosensing experiments. Graphene nanopores may lead to sensing devices where the electric potential is controlled locally at the nanopore and transverse current can be measured across the pore aperture. Although artificial nanopore technology is at its infancy, we believe that it holds a tremendous potential for single-molecule sensing as well as single-cell analysis and manipulation.

\section{Acknowledgements}

Xiang Li, and Michelle Maalouf are gratefully acknowledged for critical reading of the manuscript. This work was supported in part by grants from the National Aeronautics and Space Administration Cooperative Agreements NCC9-165 and NNX08BA47A, and the National Institutes of Health [P01-HG000205].

\section{References}

Actis, P.; Jejelowo, O. \& Pourmand, N. (2010). Ultrasensitive mycotoxin detection by STING sensors. Biosensors and Bioelectronics, Vol.26, No.2, pp. 333-337, 0956-5663

Actis, P.; Vilozny, B.; Seger, R. A.; Li, X.; Jejelowo, O.; Rinaudo, M. \& Pourmand, N. (2011). Voltage-Controlled Metal Binding on Polyelectrolyte-Functionalized Nanopores. Langmuir, Vol.27, No.10, pp. 6528-6533, 0743-7463

Akeson, M.; Branton, D.; Kasianowicz, J. J.; Brandin, E. \& Deamer, D. W. (1999). Microsecond Time-Scale Discrimination Among Polycytidylic Acid, Polyadenylic Acid, and Polyuridylic Acid as Homopolymers or as Segments Within Single RNA Molecules. Biophysical Journal, Vol.77, No.6, pp. 3227-3233, 0006-3495

Actis, P.; Rogers, A.; Nivala, J.; Vilozny, B.; Seger, R. A.; Jejelowo, O. \& Pourmand, N. (2011) Reversible Thrombin Detection by Aptamer functionalized STING sensors. Biosensors and Bioelectronics, Vol.26, No.11, pp. 4503-4507, 0956-5663.

Ali, M.; Yameen, B.; Neumann, R.; Ensinger, W.; Knoll, W. \& Azzaroni, O. (2008). Biosensing and Supramolecular Bioconjugation in Single Conical Polymer Nanochannels. Facile Incorporation of Biorecognition Elements into Nanoconfined Geometries. 
Journal of the American Chemical Society, Vol.130, No.48, (2008/12/03), pp. 16351$16357,0002-7863$

Alvarez, S. D.; Li, C.-P.; Chiang, C. E.; Schuller, I. K. \& Sailor, M. J. (2009). A Label-Free Porous Alumina Interferometric Immunosensor. ACS Nano, Vol.3, No.10, pp. 33013307, 1936-0851

Branton, D.; Deamer, D. W.; Marziali, A.; Bayley, H.; Benner, S. A.; Butler, T.; Di Ventra, M.; Garaj, S.; Hibbs, A.; Huang, X.; Jovanovich, S. B.; Krstic, P. S.; Lindsay, S.; Ling, X. S.; Mastrangelo, C. H.; Meller, A.; Oliver, J. S.; Pershin, Y. V.; Ramsey, J. M.; Riehn, R.; Soni, G. V.; Tabard-Cossa, V.; Wanunu, M.; Wiggin, M. \& Schloss, J. A. (2008). The potential and challenges of nanopore sequencing. Nat Biotech, Vol.26, No.10, pp. 1146-1153, 1087-0156

de la Escosura-Muñiz, A. \& Merkoçi, A. (2011). A Nanochannel/Nanoparticle-Based Filtering and Sensing Platform for Direct Detection of a Cancer Biomarker in Blood. Small, Vol.7, No.5, pp. 675-682, 1613-6829

Ding, C.; Li, H.; Hu, K. \& Lin, J.-M. (2010). Electrochemical immunoassay of hepatitis B surface antigen by the amplification of gold nanoparticles based on the nanoporous gold electrode. Talanta, Vol.80, No.3, pp. 1385-1391, 0039-9140

Ding, S.; Gao, C. \& Gu, L.-Q. (2009). Capturing Single Molecules of Immunoglobulin and Ricin with an Aptamer-Encoded Glass Nanopore. Analytical Chemistry, Vol.81, No.16, pp. 6649-6655, 0003-2700

Ding, Y.; Kim, Y. J. \& Erlebacher, J. (2004). Nanoporous Gold Leaf: “Ancient Technology" / Advanced Material. Advanced Materials, Vol.16, No.21, pp. 1897-1900, 1521-4095

Ellington, A. D. \& Szostak, J. W. (1990). In vitro selection of RNA molecules that bind specific ligands. Nature, Vol.346, No.6287, pp. 818-822,

Freedman, J. R.; Mattia, D.; Korneva, G.; Gogotsi, Y.; Friedman, G. \& Fontecchio, A. K. (2007). Magnetically assembled carbon nanotube tipped pipettes. Applied Physics Letters, Vol.90, No.10, pp. 103108,

Fu, Y.; Tokuhisa, H. \& Baker, L. A. (2009). Nanopore DNA sensors based on dendrimermodified nanopipettes. Chem Commun (Camb), No.32, (Aug 28), pp. 4877-4879, 1364548X (Electronic) 1359-7345 (Linking)

Garaj, S.; Hubbard, W.; Reina, A.; Kong, J.; Branton, D. \& Golovchenko, J. A. (2010). Graphene as a subnanometre trans-electrode membrane. Nature, Vol.467, No.7312, pp. 190-193, 0028-0836

Geim, A. K. \& Novoselov, K. S. (2007). The rise of graphene. Nat Mater, Vol.6, No.3, pp. 183$191,1476-1122$

Gyurcsányi, R. E. (2008). Chemically-modified nanopores for sensing. TrAC Trends in Analytical Chemistry, Vol.27, No.7, pp. 627-639, 0165-9936

Han, A.; Creus, M.; Schürmann, G.; Linder, V.; Ward, T. R.; de Rooij, N. F. \& Staufer, U. (2008). Label-Free Detection of Single Protein Molecules and Protein-Protein Interactions Using Synthetic Nanopores. Analytical Chemistry, Vol.80, No.12, (2008/06/01), pp. 4651$4658,0003-2700$

Hansma, P.; Drake, B.; Marti, O.; Gould, S. \& Prater, C. (1989). The scanning ionconductance microscope. Science, Vol.243, No.4891, (February 3, 1989), pp. 641-643,

Harrell, C. C.; Choi, Y.; Horne, L. P.; Baker, L. A.; Siwy, Z. S. \& Martin, C. R. (2006). Resistive-Pulse DNA Detection with a Conical Nanopore Sensort. Langmuir, Vol.22, No.25, pp. 10837-10843, 0743-7463 
Jágerszki, G.; Gyurcsányi, R. E.; Höfler, L. \& Pretsch, E. (2007). Hybridization-Modulated Ion Fluxes through Peptide-Nucleic-Acid- Functionalized Gold Nanotubes. A New Approach to Quantitative Label-Free DNA Analysis. Nano Letters, Vol.7, No.6, (2007/06/01), pp. 1609-1612, 1530-6984

Kasianowicz, J. J.; Brandin, E.; Branton, D. \& Deamer, D. W. (1996). Characterization of individual polynucleotide molecules using a membrane channel. Proceedings of the National Academy of Sciences, Vol.93, No.24, (November 26, 1996), pp. 13770-13773,

Kim, B. M.; Murray, T. \& Bau, H. H. (2005). The fabrication of integrated carbon pipes with sub-micron diameters. Nanotechnology, No.8, pp. 1317, 0957-4484

Kim, M. J.; Wanunu, M.; Bell, D. C. \& Meller, A. (2006). Rapid Fabrication of Uniformly Sized Nanopores and Nanopore Arrays for Parallel DNA Analysis. Advanced Materials, Vol.18, No.23, pp. 3149-3153, 1521-4095

Klenerman, D. \& Korchev, Y. (2006). Potential biomedical applications of the scanned nanopipette. Nanomedicine (Lond), Vol.1, No.1, (Jun), pp. 107-114, 1748-6963 (Electronic) 1743-5889 (Linking)

Krapf, D.; Wu, M.-Y.; Smeets, R. M. M.; Zandbergen, H. W.; Dekker, C. \& Lemay, S. G. (2005). Fabrication and Characterization of Nanopore-Based Electrodes with Radii down to $2 \mathrm{~nm}$. Nano Letters, Vol.6, No.1, pp. 105-109, 1530-6984

Lee, J.; Sohn, K. \& Hyeon, T. (2001). Fabrication of Novel Mesocellular Carbon Foams with Uniform Ultralarge Mesopores. Journal of the American Chemical Society, Vol.123, No.21, pp. 5146-5147, 0002-7863

Lei, Y.; Xie, F.; Wang, W.; Wu, W. \& Li, Z. (2010). Suspended nanoparticle crystal (S-NPC): A nanofluidics-based, electrical read-out biosensor. Lab on a Chip, Vol.10, No.18, pp. 2338-2340, 1473-0197

Li, J.; Stein, D.; McMullan, C.; Branton, D.; Aziz, M. J. \& Golovchenko, J. A. (2001). Ion-beam sculpting at nanometre length scales. Nature, Vol.412, No.6843, pp. 166-169, 0028-0836

Li, R.; Wu, D.; Li, H.; Xu, C.; Wang, H.; Zhao, Y.; Cai, Y.; Wei, Q. \& Du, B. (2011). Label-free amperometric immunosensor for the detection of human serum chorionic gonadotropin based on nanoporous gold and graphene. Analytical Biochemistry, Vol.414, No.2, pp. 196-201, 0003-2697

Li, X.; Wang, R. \& Zhang, X. (2011). Electrochemiluminescence immunoassay at a nanoporous gold leaf electrode and using $\mathrm{CdTe}$ quantun dots as labels. Microchimica Acta, Vol.172, No.3, pp. 285-290, 0026-3672

Lin, J.; He, C. \& Zhang, S. (2009). Immunoassay channels for a-fetoprotein based on encapsulation of biorecognition molecules into SBA-15 mesopores. Analytica Chimica Acta, Vol.643, No.1-2, pp. 90-94, 0003-2670

Lin, K.-C.; Kunduru, V.; Bothara, M.; Rege, K.; Prasad, S. \& Ramakrishna, B. L. (2010). Biogenic nanoporous silica-based sensor for enhanced electrochemical detection of cardiovascular biomarkers proteins. Biosensors and Bioelectronics, Vol.25, No.10, pp. 2336-2342, 0956-5663

Martin, C. R.; Nishizawa, M.; Jirage, K. \& Kang, M. (2001). Investigations of the Transport Properties of Gold Nanotubule Membranes. The Journal of Physical Chemistry B, Vol.105, No.10, pp. 1925-1934, 1520-6106

Merchant, C. A.; Healy, K.; Wanunu, M.; Ray, V.; Peterman, N.; Bartel, J.; Fischbein, M. D.; Venta, K.; Luo, Z.; Johnson, A. T. C. \& Drndic, M. (2010). DNA Translocation through Graphene Nanopores. Nano Letters, Vol.10, No.8, pp. 2915-2921, 1530-6984

Morris, R. E. \& Wheatley, P. S. (2008). Gas Storage in Nanoporous Materials. Angewandte Chemie International Edition, Vol.47, No.27, pp. 4966-4981, 1521-3773 
Movileanu, L. (2009). Interrogating single proteins through nanopores: challenges and opportunities. Trends in Biotechnology, Vol.27, No.6, pp. 333-341, 0167-7799

Nguyen, B. T. T.; Koh, G.; Lim, H. S.; Chua, A. J. S.; Ng, M. M. L. \& Toh, C.-S. (2009). Membrane-Based Electrochemical Nanobiosensor for the Detection of Virus. Analytical Chemistry, Vol.81, No.17, pp. 7226-7234, 0003-2700

Nguyen, G.; Howorka, S. \& Siwy, Z. (2011). DNA Strands Attached Inside Single Conical Nanopores: Ionic Pore Characteristics and Insight into DNA Biophysics. Journal of Membrane Biology, Vol.239, No.1, pp. 105-113, 0022-2631

Oukhaled, A.; Cressiot, B.; Bacri, L.; Pastoriza-Gallego, M.; Betton, J.-M.; Bourhis, E.; Jede, R.; Gierak, J.; Auvray, L. c. \& Pelta, J. (2011). Dynamics of Completely Unfolded and Native Proteins through Solid-State Nanopores as a Function of Electric Driving Force. ACS Nano, Vol.5, No.5, (2011/05/24), pp. 3628-3638, 1936-0851

Piao, Y.; Lee, D.; Kim, J.; Kim, J.; Hyeon, T. \& Kim, H.-S. (2009). High performance immunoassay using immobilized enzyme in nanoporous carbon. Analyst, Vol.134, No.5, pp. 926-932, 0003-2654

Piao, Y.; Lee, D.; Lee, J.; Hyeon, T.; Kim, J. \& Kim, H.-S. (2009). Multiplexed immunoassay using the stabilized enzymes in mesoporous silica. Biosensors and Bioelectronics, Vol.25, No.4, pp. 906-912, 0956-5663

Saleh, O. A. \& Sohn, L. L. (2003). Direct detection of antibody-antigen binding using an onchip artificial pore. Proceedings of the National Academy of Sciences, Vol.100, No.3, (February 4, 2003), pp. 820-824,

Schmidt-Winkel, P.; Lukens, W. W.; Zhao, D.; Yang, P.; Chmelka, B. F. \& Stucky, G. D. (1998). Mesocellular Siliceous Foams with Uniformly Sized Cells and Windows. Journal of the American Chemical Society, Vol.121, No.1, pp. 254-255, 0002-7863

Schneider, G. g. F.; Kowalczyk, S. W.; Calado, V. E.; Pandraud, G. g.; Zandbergen, H. W.; Vandersypen, L. M. K. \& Dekker, C. (2010). DNA Translocation through Graphene Nanopores. Nano Letters, Vol.10, No.8, pp. 3163-3167, 1530-6984

Sexton, L. T.; Horne, L. P.; Sherrill, S. A.; Bishop, G. W.; Baker, L. A. \& Martin, C. R. (2007). Resistive-Pulse Studies of Proteins and Protein/Antibody Complexes Using a Conical Nanotube Sensor. Journal of the American Chemical Society, Vol.129, No.43, pp. 13144-13152, 0002-7863

Sexton, L. T.; Mukaibo, H.; Katira, P.; Hess, H.; Sherrill, S. A.; Horne, L. P. \& Martin, C. R. (2010). An Adsorption-Based Model for Pulse Duration in Resistive-Pulse Protein Sensing. Journal of the American Chemical Society, Vol.132, No.19, (2010/05/19), pp. 6755-6763, 0002-7863

Shulga, O. V.; Zhou, D.; Demchenko, A. V. \& Stine, K. J. (2008). Detection of free prostate specific antigen (fPSA) on a nanoporous gold platform. Analyst, Vol.133, No.3, pp. 319-322, 0003-2654

Singh, R.; Sharma, P. P.; Baltus, R. E. \& Suni, I. I. (2010). Nanopore immunosensor for peanut protein Ara h1. Sensors and Actuators B: Chemical, Vol.145, No.1, pp. 98-103, 0925-4005

Siwy, Z.; Apel, P.; Dobrev, D.; Neumann, R.; Spohr, R.; Trautmann, C. \& Voss, K. (2003). Ion transport through asymmetric nanopores prepared by ion track etching. Nuclear Instruments and Methods in Physics Research Section B: Beam Interactions with Materials and Atoms, Vol.208, pp. 143-148, 0168-583X

Siwy, Z. S. \& Howorka, S. (2010). Engineered voltage-responsive nanopores. Chemical Society Reviews, Vol.39, No.3, pp. 1115-1132, 0306-0012 
Song, L.; Hobaugh, M. R.; Shustak, C.; Cheley, S.; Bayley, H. \& Gouaux, J. E. (1996). Structure of Staphylococcal a-Hemolysin, a Heptameric Transmembrane Pore. Science, Vol.274, No.5294, (December 13, 1996), pp. 1859-1865,

Storm, A. J.; Chen, J. H.; Ling, X. S.; Zandbergen, H. W. \& Dekker, C. (2003). Fabrication of solid-state nanopores with single-nanometre precision. Nat Mater, Vol.2, No.8, pp. 537-540, 1476-1122

Stroeve, P. \& Ileri, N. (2011). Biotechnical and other applications of nanoporous membranes. Trends in Biotechnology, Vol.29, No.6, pp. 259-266, 0167-7799

Tripathi, A.; Wang, J.; Luck, L. A. \& Suni, I. I. (2006). Nanobiosensor Design Utilizing a Periplasmic E. coli Receptor Protein Immobilized within Au/Polycarbonate Nanopores. Analytical Chemistry, Vol.79, No.3, (2007/02/01), pp. 1266-1270, 0003-2700

Tuerk, C. \& Gold, L. (1990). Systematic evolution of ligands by exponential enrichment: RNA ligands to bacteriophage T4 DNA polymerase. Science, Vol.249, No.4968, (August 3, 1990), pp. 505-510,

Umehara, S.; Pourmand, N.; Webb, C. D.; Davis, R. W.; Yasuda, K. \& Karhanek, M. (2006). Current Rectification with Poly-l-Lysine-Coated Quartz Nanopipettes. Nano Letters, Vol.6, No.11, pp. 2486-2492, 1530-6984

Umehara, S.; Karhanek, M.; Davis, R. W. \& Pourmand, N. (2009). Label-free biosensing with functionalized nanopipette probes. Proceedings of the National Academy of Sciences, Vol.106, No.12, (March 24, 2009), pp. 4611-4616,

Uram, J. D.; Ke, K.; Hunt, A. J. \& Mayer, M. (2006). Submicrometer Pore-Based Characterization and Quantification of Antibody-Virus Interactions. Small, Vol.2, No.8-9, pp. 967-972, 1613-6829

Vlassiouk, I.; Kozel, T. R. \& Siwy, Z. S. (2009). Biosensing with Nanofluidic Diodes. Journal of the American Chemical Society, Vol.131, No.23, (2009/06/17), pp. 8211-8220, 0002-7863

Wang, X. \& Smirnov, S. (2009). Label-Free DNA Sensor Based on Surface Charge Modulated Ionic Conductance. ACS Nano, Vol.3, No.4, (2009/04/28), pp. 1004-1010, 1936-0851

Wang, Y. \& Caruso, F. (2004). Enzyme encapsulation in nanoporous silica spheres. Chemical Communications, No.13, pp. 1528-1529, 1359-7345

Wanunu, M. \& Meller, A. (2007). Chemically Modified Solid-State Nanopores. Nano Letters, Vol.7, No.6, pp. 1580-1585, 1530-6984

Wei, C.; Bard, A. J. \& Feldberg, S. W. (1997). Current Rectification at Quartz Nanopipet Electrodes. Analytical Chemistry, Vol.69, No.22, pp. 4627-4633, 0003-2700

Wei, Q.; Zhao, Y.; Xu, C.; Wu, D.; Cai, Y.; He, J.; Li, H.; Du, B. \& Yang, M. (2011). Nanoporous gold film based immunosensor for label-free detection of cancer biomarker. Biosensors and Bioelectronics, Vol.26, No.8, pp. 3714-3718, 0956-5663

Yang, Z.; Xie, Z.; Liu, H.; Yan, F. \& Ju, H. (2008). Streptavidin-Functionalized ThreeDimensional Ordered Nanoporous Silica Film for Highly Efficient Chemiluminescent Immunosensing. Advanced Functional Materials, Vol.18, No.24, pp. 3991-3998, 1616-3028

Yusko, E. C.; Johnson, J. M.; Majd, S.; Prangkio, P.; Rollings, R. C.; Li, J.; Yang, J. \& Mayer, M. (2011). Controlling protein translocation through nanopores with bio-inspired fluid walls. Nat Nano, Vol.6, No.4, pp. 253-260, 1748-3387

Zandbergen, H. W.; van Duuren, R. J. H. A.; Alkemade, P. F. A.; Lientschnig, G.; Vasquez, O.; Dekker, C. \& Tichelaar, F. D. (2005). Sculpting Nanoelectrodes with a Transmission Electron Beam for Electrical and Geometrical Characterization of Nanoparticles. Nano Letters, Vol.5, No.3, pp. 549-553, 1530-6984

Zhang, B.; Zhang, Y. \& White, H. S. (2004). The Nanopore Electrode. Analytical Chemistry, Vol.76, No.21, pp. 6229-6238, 0003-2700 


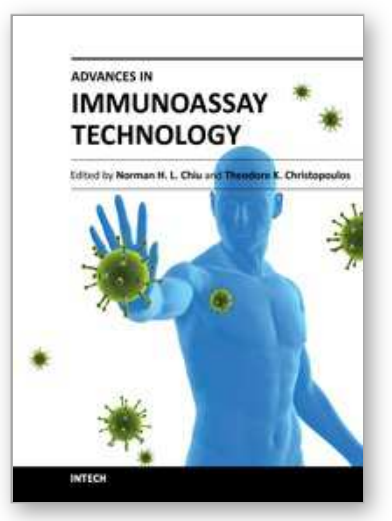

\author{
Advances in Immunoassay Technology \\ Edited by Dr. Norman H. L. Chiu
}

ISBN 978-953-51-0440-7

Hard cover, 180 pages

Publisher InTech

Published online 23, March, 2012

Published in print edition March, 2012

From the basic in vitro study of a specific biomolecule to the diagnosis or prognosis of a specific disease, one of the most widely used technology is immunoassays. By using a specific antibody to recognize the biomolecule of interest, relatively high specificity can be achieved by immunoassays, such that complex biofluids (e.g. serum, urine, etc.) can be analyzed directly. In addition to the binding specificity, the other key features of immunoassays include relatively high sensitivity for the detection of antibody-antigen complexes, and a wide dynamic range for quantitation. Over the past decade, the development and applications of immunoassays have continued to grow exponentially. This book focuses on some of the latest technologies for the development of new immunoassays.

\title{
How to reference
}

In order to correctly reference this scholarly work, feel free to copy and paste the following:

Paolo Actis, Boaz Vilozny and Nader Pourmand (2012). Immunoassays Using Artificial Nanopores, Advances in Immunoassay Technology, Dr. Norman H. L. Chiu (Ed.), ISBN: 978-953-51-0440-7, InTech, Available from: http://www.intechopen.com/books/advances-in-immunoassay-technology/immunoassays-using-artificialnanopores

\section{INTECH}

open science | open minds

\section{InTech Europe}

University Campus STeP Ri

Slavka Krautzeka 83/A

51000 Rijeka, Croatia

Phone: +385 (51) 770447

Fax: +385 (51) 686166

www.intechopen.com

\section{InTech China}

Unit 405, Office Block, Hotel Equatorial Shanghai

No.65, Yan An Road (West), Shanghai, 200040, China

中国上海市延安西路65号上海国际贵都大饭店办公楼405单元

Phone: $+86-21-62489820$

Fax: +86-21-62489821 
(C) 2012 The Author(s). Licensee IntechOpen. This is an open access article distributed under the terms of the Creative Commons Attribution 3.0 License, which permits unrestricted use, distribution, and reproduction in any medium, provided the original work is properly cited. 